\title{
Energy Efficiency and Recycled Building Materials in Case of Cellular Glass - Glass Brick
}

\author{
Mohammadjavad Mahdavinejad ${ }^{1}$, Seyedmohammadhadi Shapourian ${ }^{2}$, Razieh Boloorchian ${ }^{3}$, Ali Sadraie ${ }^{4, *}$ \\ ${ }^{1}$ Assistant Professor, Faculty of Art and Architecture, Tarbiat Modares University, Tehran, Iran \\ ${ }^{2}$ Energy \& Architecture Group, Faculty of Art and Architecture,Tehran University, Tehran, Iran \\ ${ }^{3}$ Young Researchers Club,Central Tehran Branch,Islamic Azad University, Tehran, Iran \\ ${ }^{4}$ Master of Architecture, Kish International Campus, Tehran University, Shiraz, Iran \\ *Corresponding author: ali.sadraie@gmail.com
}

Received October 24, 2013; Revised November 23, 2013; Accepted March 11, 2014

\begin{abstract}
Building material and components play a crucial role in solar buildings construction and planning. The literature review of the research emphasize that solar architecture and building integration is in need of some productive design strategies which focuses on reuse of recycled building materials. This paper aims at suggesting a mechanism for optimal use of recycled materials in construction industry which serve energy efficiency as one of the top priorities. The research questions are: 1- what are the priorities of using recycled material as related to energy efficiency issues? 2- Which recycled materials can be used in construction to meet energy efficiency in solar buildings? Recycled cellular glass is selected as research sample to develop inference mechanism. A combination of qualitative and quantitative methods as well as problem solving approach are used in this study to answer the research questions related to construction industry particularly energy protection. The findings indicate increase in energy price and increase in the difference between cost of melting raw materials and melting recycled glass; and enactment of regulations for reducing extraction of raw materials and using recycled ones instead in construction projects can significantly affect the cost-effectiveness of using recycled materials in producing cellular glass; especially in contemporary architecture and future ZEB sustecture. In the other word recycled building materials can be adopted in solar architecture to energy efficiency.
\end{abstract}

Keywords: recycled materials, contemporary architecture, ZEB, sustecture, glass brick

Cite This Article: Mohammadjavad Mahdavinejad, Seyedmohammadhadi Shapourian, Razieh Boloorchian, and Ali Sadraie, "Energy Efficiency and Recycled Building Materials in Case of Cellular Glass - Glass Brick." American Journal of Energy Research, vol. 2, no. 1 (2014): 18-23. doi: 10.12691/ajer-2-1-3.

\section{Introduction}

Changing people's attitude toward the world, regarding the potential of recyclable resources increase is rooted in the not very far crisis and fear which the world and human societies have ahead. Soon finishing the natural resources became a considerable worry for industry and economical trades, while the population grew and human exploitation of resources increased. Using recycled materials has been a respond to the challenge. There is an emphasis on using recycled materials due to the pollution and waste disposal. Today, recycling is considered as a prioritized scientific strategy and goal in urban management in developed countries, and in the recent decades, it has been considered as a basis and goal in our country as well mostly because of the civilization growth, technology development, consumption pattern changes and the risk of environmental destruction. Most materials are disintegrated in nature and can be recycled automatically. Unfortunately, great amount of garbage and waste like plastic cannot be disintegrated and remain for hundreds of years in nature. Even if they are cut in pieces, still they remain non- biodegradable and pollute the earth and water gradually cause environmental pollution. Although, big and populated cities like Tehran face the ever-increasing garbage collection, disposal and recycling problems, which are one of the most important worries of people in charge, any suggestion and guideline through recycling these materials can be considerable. In addition, green architecture and eco-friendly architectural design [1] has a lot to do with technical factors. [2] According to the discussed issues in Iran contemporary architecture, energy has a great value of intention and day by day we can see more hoes important it is [3]. Energy has a high place in architectural theories, whether in designing or in construction [4]. Important role of architecture in designing is one of the subjects that need study in families and in industry and in professional society and therefore we can reach developed context of sustainable architecture science $[5,6,7]$. Nowadays, energy is one of the main challenges in developing countries contemporary architecture and prior observation shows that these countries do not have acceptable qualification in clean energies consumption [8]. With great intention of using green technologies, Regarding to clean energies is a part of movement, clean and healthy model in humans' life [9]. The literature review of the 
research shows that challenges and opportunities regarding adoption of clean energy technology in developing countries are of the most important issues, especially Middle East countries such as Iran though they enjoy prosperous oil wells.

\subsection{Literature Review}

\subsubsection{Shifting to Future Sustecture}

Sustainable architecture discussion with an emphasis on sustainable technology refers as Sustecture is issue that follow environmental and reduce energy waste. In this architecture, the building tries to adapt to climatic conditions of the region and interact with it. As Richard Rogers said the buildings are like birds in winter dressed their feathers to adapt it to regulate based on metabolic adaptation. Today, the term sustainability is used for a wide range of sensitive approaches to environment, from traditional architecture known as a kind of ecological sustainability and social architecture to others which have endeavord with reconciliation and the interaction between technology and ecology to operate both useful features. In sustecture paradigm the most important aspects of contemporary architecture of developing countries should meet sustainable development goals and objectives.

\subsubsection{Significance of Sustecture}

Statistics indicates that: $1-75$ per cent of the waste is produced in cities. 2- Disintegrating of many plastic items in nature takes 300 years. 3- In terms of environment, Iran is the 132nd among all 146 countries in the world. 4- In addition to producing 400 to 600 liter run-off, per ton of garbage can ascend 400 cube meters of gas emission. 52/5 million tons of dried garbage are left in Tehran annually. 6- Recycling 30 per cent of Tehran's dried garbage costs 357 billion Rials. These items mentioned above indicate that recycling garbage is absolutely beneficial and not only does this process reduce the environmental pollution but also it has plenty of economic advantages which decrease the amount of disposing garbage to the environment. Therefore, general hygiene is improved and many diseases are reduced, extraction of raw materials is less required and natural resources are protected for future generations. By execution of recycling and reducing the amount of garbage, the cost of garbage collection, transportation and burial is decreased and considering the national economy, importing raw materials is less needed which leads to economic independence decrease and national production increase.

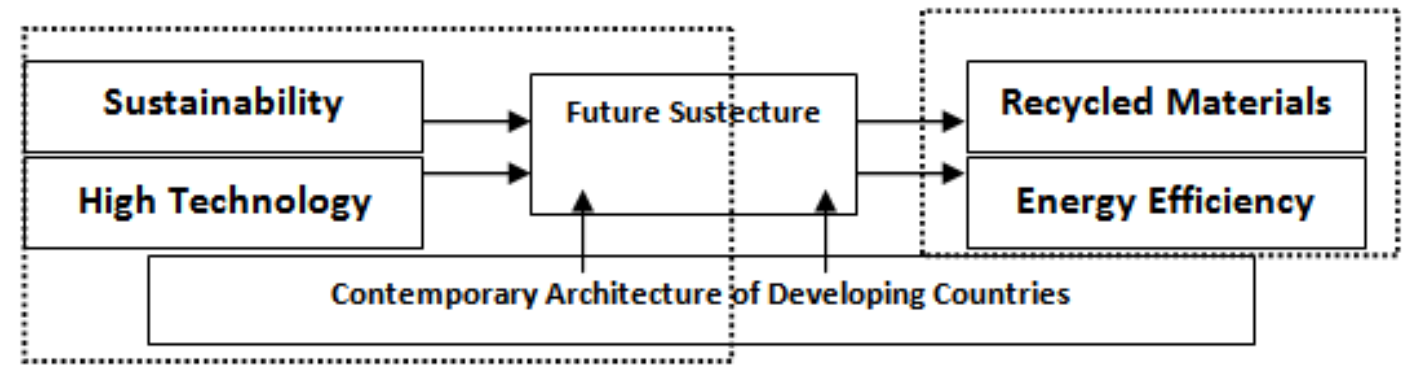

Figure 1. Reuse of recycled materials as a way to future sustecture

\section{Materials and Methods}

This paper aims at suggesting a mechanism for optimal use of recycled materials in construction industry which serve energy efficiency as one of the top priorities. The research questions are: 1- what are the priorities of using recycled material as related to energy efficiency issues? 2Which recycled materials can be used in construction to meet energy efficiency in solar buildings? Recycled cellular glass is selected as research sample to develop inference mechanism. A combination of qualitative and quantitative methods as well as problem solving approach are used in this study to answer the research questions related to construction industry particularly energy protection.

\section{Recycled Materials and Environmental Protection}

Current approach of using renewable sources of the earth in the production of green materials indicates the important role of recycling. Although still there is some resistance against use of green materials, gradually with technological advances in the production of certain materials, these concerns have reduced. The potential of non-toxic green materials in reducing the environmental cost is one of their unique capabilities. Gradually, with reduction in the land resources and use of raw materials in production, we will be faced with higher prices for raw materials. This shows the importance and necessity recycling and using recycled materials in the production process. According to scientific resources, recycling process and waste reduction programs are among the priorities of solid waste management [10]. Diverse herbal products, products with recycled contents, and non-toxic and energy efficient products are typical product ecofriendly materials. The main materials which are now being recycled include: aluminium, paper, plastic, glass, ferrous metals, non-ferrous metals, garden wastes, and construction and demolition wastes. Physical analysis of wastes and the percentage of their component materials in Iran's cities show that useful materials such as paper, plastic, metals, glass and compostable materials are present in wastes. Isolation and separation of these materials in addition to reducing the volume of waste and saving money in urban waste management systems, is a good source for production of useful materials and energy.

Recycling can be done in two methods of closed and open loop processes. In the closed loop process, materials are recycled back to the main form and take exactly their original properties and initial applications. In the open loop process, recycled materials are used in other production processes as a starting point or as raw 
materials [11]. Due to the increasing volume of municipal waste including wastes resulting from the demolition of buildings and old urban contexts, especially in big cities, and the many problems resulting from unprincipled and non-technical disposal of waste materials, recycling has received a lot of attention in recent years. The increase in prices of construction materials in recent years and the recognition of the need to increase productivity in the construction industry in our country has caused employers and contractors to seek ways to reduce their civil project costs and relevant organizations are trying to reduce the environmental impact of construction wastes. Waste managing and recycling plans if well implemented can increase productivity of materials in the construction industry and prevent environmental pollutions.

\subsection{Reasons for Recycling Materials}

The recycling process not only protects environment against pollutions, but also has numerous benefits:

- Due to the lack or shortage of suitable land for waste disposal, recycling wastes and reducing their volume increase the land potential for the accepting waste materials.

- Due to limited natural resources, recycling can reduce the need to extract raw materials and natural resources will be reserved for future generations.

- The recycling operation reduces the volume of incoming waste to environment which result in reduction of pollutions and diseases as well as promotion of public health.

- Recycling reduces waste volume which can lower costs of collection, transportation and disposal of waste.

- Recycling reduces the need for importing materials from abroad, hence reduces economic dependency, and increases national output [11].

\section{Green Construction Materials}

Green construction materials use land resources and are implemented in an eco-friendly way. They recognize the restriction of non-renewable resources (such as iron ore, coal, etc.). These materials operate with a natural cycle and in relationship with ecosystem. Green building materials are nontoxic. They take into account energy efficiency and productivity of water resources. They are green at different stages of generation, use and reuse. They have received high scores because of their role in management of resources, their impact on environmental quality of indoor conditions, and their efficiency (energy and water efficiency). Ideally, these products are marked with using the least amount of permanent or renewable resources.

\subsection{Benefits of Using Green Materials}

Using green building materials can result in higher indoor air quality (IAQ), better satisfaction of users' needs, and compliance with the requirements set by regulations. Concerns about construction of healthy buildings and places are increasing as a result of increase in our understanding of the risks associated with known materials. Asbestos and lead are old examples in this regard. Green building materials, which are particularly made of non-toxic, natural and organic materials, can reduce indoor air pollution and the discontent caused by it.

\subsection{Recycled Materials in Green Architecture}

Today, preserving the natural environment and protecting human health and welfare and rights of future generations are among important things that should be taken into account in all human measures. Recycling not only helps us preserve natural resources and protect the environment, but also is economical as it uses scientific methods. A major portion of fuel resources is consumed in buildings. A major portion of fuel resources is consumed in buildings, which in turn leads to environmental crisis. Therefore, developing green architecture is an appropriate solution to this problem. The main materials that are now being recycled are: aluminium, plastic, glass, ferrous metals, nonferrous metals, construction and destruction waste and debris, and so on. Construction and destruction waste and debris and their uses are included in Table 1:

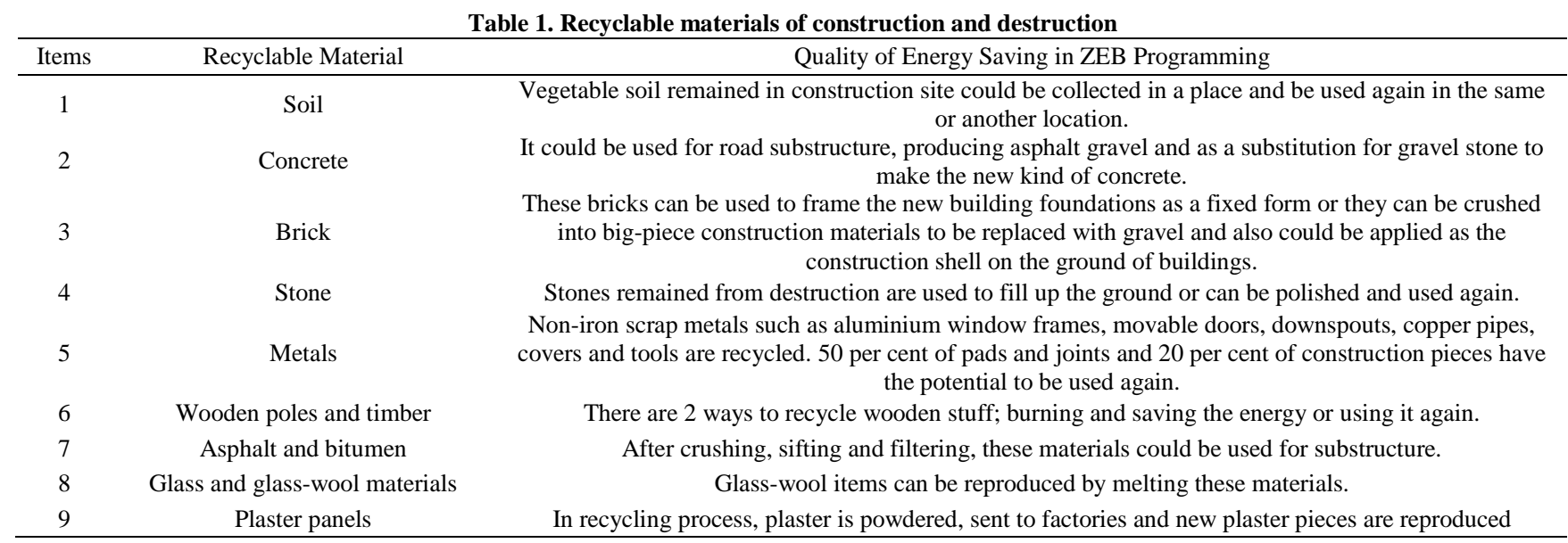

\section{Discussion}

Currently, due to lower prices of raw materials contractors are reluctant to use recycled materials to produce construction materials. If regulations require the use of recycled materials in the production process and also require the use of recycled materials relative to the cost of construction, it can increase the use of recycled products. To evaluate the use of recycled materials in the production of thermal insulation cellular glass thermal 
insulation is investigated as an example here. In the process of producing cellular glass insulation, recycled glass can be used with the aim of improving environmental conditions, reducing costs for manufacturers and also reducing the length of return on investment period. In this regard, the return on investment diagram for cellular glass and optimum thickness of insulation is drawn.

\subsection{Cellular Glass (Sponge Glass)}

Cellular glass is a thermal insulation made of glass added with adequate foaming agents with a structure of equally closed cells (National Standard 80 84, paragraph 3.4). This type of insulation is produced in the forms of boards and tubes with a temperature range between - $40^{\circ}$ $\mathrm{C}$ to $482^{\circ} \mathrm{C}$. It has a low thermal conductivity in low temperature and has a low wearing and corrosion resistance. And its ability to absorb sound is good. The raw material for cellular glass production is the mix of fine powder grinded glass with a foaming material. Around $60 \%$ of the glass powder can be derived from recycled materials.

\subsection{Using Recycled Materials Manufacturing Cellular Glass}

Currently, several companies in the country produce cellular glass. Although, recycled glass has been used around the world to produce cellular glass and an average 50 percent of raw materials on these plants are recycled glass, in Iran, due to lower prices of raw materials contractors are reluctant to use recycled materials to produce construction materials. Although according to studies done in Iran, price increase resulting from the use of recycled materials compared with current production trend is 100 to 200 IRR per Kg. no measure has been taken in this regard so far. With increase in energy price (increase in the difference between cost of melting raw materials and that of melting recycled glass) and enactment of regulations for reducing extraction of raw materials and using recycled ones instead in construction projects can significantly affect the cost-effectiveness of using recycled materials in producing cellular glass.

\subsection{Information on Cellular Glass Insulation in Buildings}

Since cellular glass insulation has a higher compressive strength than pressure bricks, it can even be used as bearing wall. Therefore, its implementation details are similar to walls with construction materials. Here, walls with the outer coating of granite stone with a thickness of $2 \mathrm{~cm}$ and the inner layer of plaster are used for calculations. Therefore, the layers of the wall from outside to inside are:

- 2-cm thick granite stone (for a good connection of groove in the stone with wire).

- 3-cm thick cement and mortar

- A layer of cellular glass

- 2.5-cm thick plastering and joinery

According to these details, the price per square meter of wall excluding the insulation was calculated as 813000 IRR. To calculate cell glass thermal insulation costs, the price enquired for each cubic meter of material was 1700000 IRR, which, based on the basic thickness considered in the calculations as much as five millimetre material per square meter was considered as 8,500 IRR. The charges of transport and workers increased the base price of material to about 32,000 IRR per cubic meter for a thickness of $5 \mathrm{~mm}$.

To calculate the cost of every $5 \mathrm{~mm}$ increase in thickness of the insulation, since in the production of this product increasing thickness in the original form is possible, and there is no other price increase save the cost of materials, only the cost of materials and transportation per $5 \mathrm{~mm}$ increase in the thickness was calculated as 10,000 IRR (Due to an increase in product volume transportation cost can be only calculated as base price).

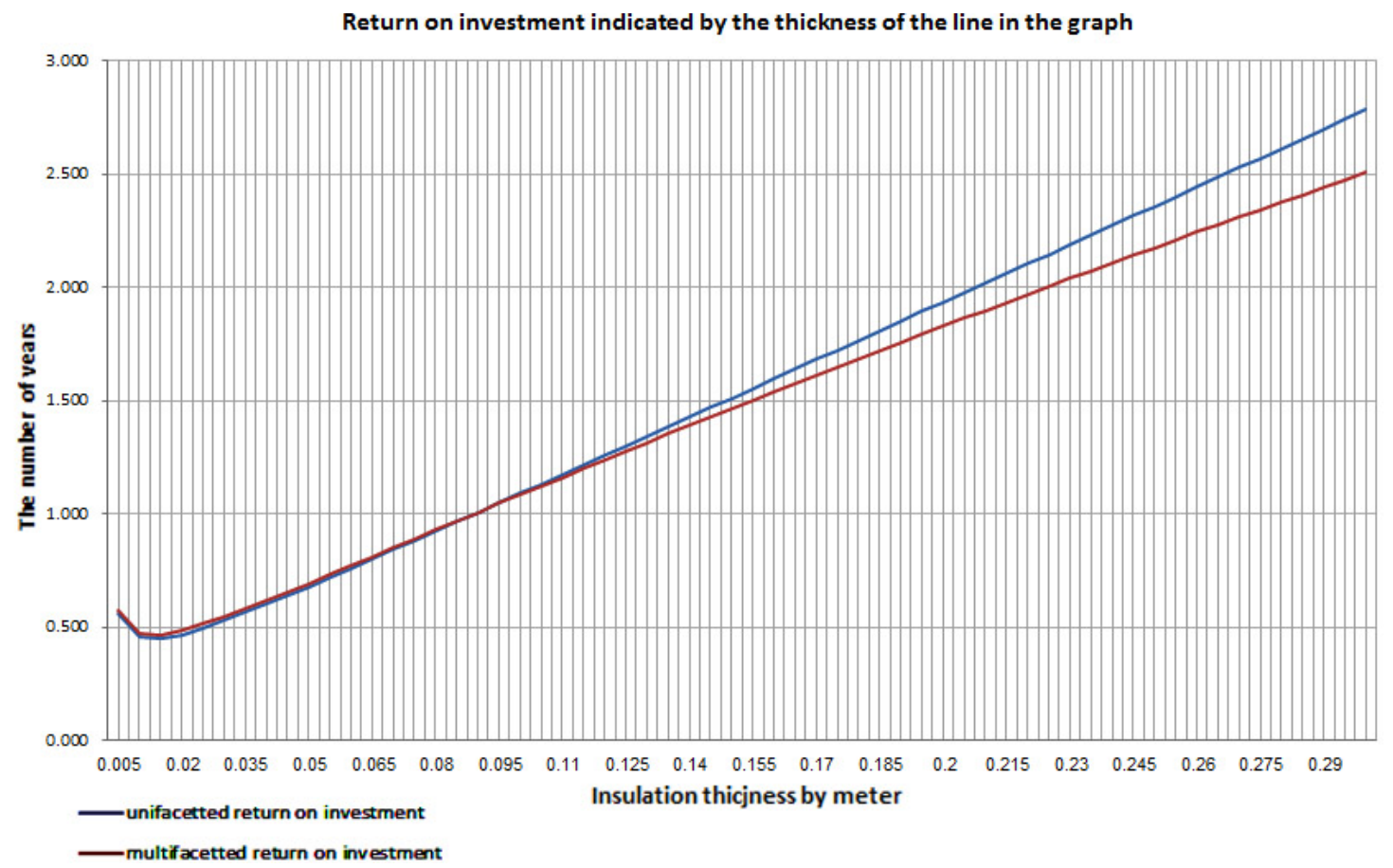

Figure 2. The calculation of the cellular glass and the return on investment chart per increase in the insulation thickness 


\subsection{Comparing Return on Investment for Cellular Glass and Recycled Cellular Glass}

With regard to return on investment calculated, the return on investment chart per increase in the insulation thickness is presented in Figure 2.

As can be seen, the optimal insulation thickness according to the specifications provided is $1.5 \mathrm{~cm}$. At this thickness, taking into account the initial cost, insulation has the maximum efficiency. In other words, the shortest period of return on investment occur at this thickness. Based on calculations, heat transfer coefficient of the entire wall with this much thickness was equivalent to 2.120 watts per square meter Kelvin. Referring to regulations provided by Article 19 of national construction regulations and investigating values of reference heat transfer coefficient of wall based on building classification, we found out that heat transfer coefficient of wall at optimum insulation thickness does not satisfy requirements provided in the regulations. Although in the functional approach, the sum of multiplying heat transfer coefficient of each part of building should be lower than reference heat transfer coefficient, taking into account the use of insulation in the wall, it is expected that this part of building have a lower heat transfer rate to compensate other parts. In calculations performed by the software, the reference heat transfer coefficient for walls of each city and weather station was taken from national building regulations. The software compares the wall heat transfer coefficient per thickness amount with the reference heat transfer coefficient and presents the minimum thickness of the insulation that satisfies the requirements of national regulations Article 19 with the shortest period of return on investment. This thickness for cellular glass was calculated as $6.5 \mathrm{~cm}$. To better understand the advantages of using cellular glass brick instead of pressure bricks in the walls, the return on investment chart for it is examined. As can be seen, the return on investment period is less than a year (178 days) which is quite remarkable. The energy costs savings over the 30-years lifetime of insulation is 46000000 IRR per square meter of wall [12].

The graph of return on investment regarding walls longevity (during thirty years)

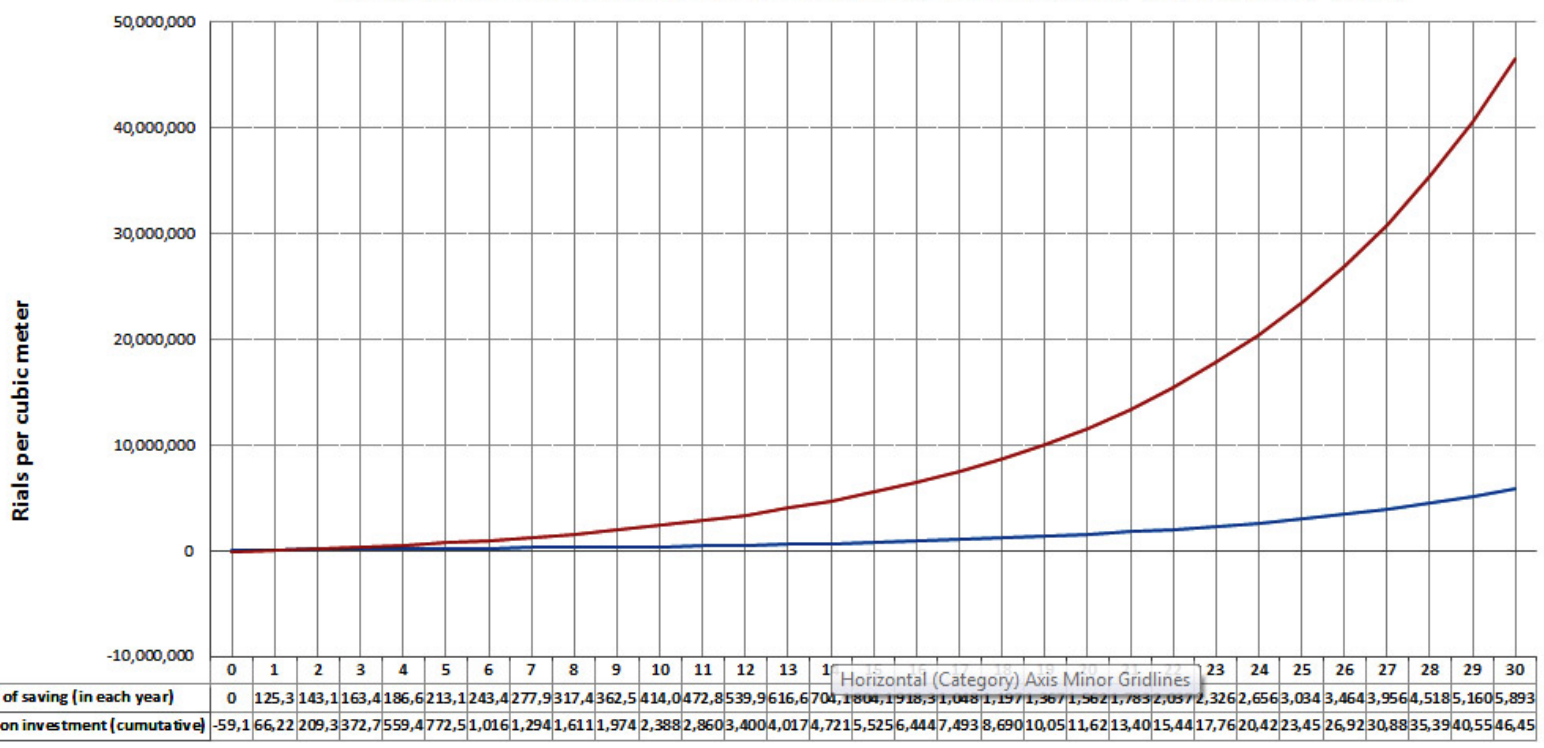

Figure 3. Comparison of pressure wall brick $(11 \mathrm{~cm})$ and cellular glass wall brick $(6.5 \mathrm{~cm})$

\section{Conclusion}

The findings indicate that with increase in energy price and increase in the difference between cost of melting raw materials and that of melting recycled glass; and enactment of regulations for reducing extraction of raw materials and using recycled ones instead in construction projects can significantly affect the cost-effectiveness of using recycled materials in producing cellular glass; especially in contemporary architecture and future ZEB sustecture. In the other word recycled building materials can be adopted in solar architecture to energy efficiency.

\section{References}

[1] Mahdavinejad, M., Ghaedi, A., Ghasempourabadi, M., Ghaedi, H. The Role of Vernacular Architecture in Design of Green Sidewalk,
Case Study: Iran, Shushtar, Applied Mechanics and Materials, 2012; Vols. 220-223: 65-68.

[2] Mahdavinejad, M., Hosseini, A., Alavibelmana, M. Enhancement HSE Factors in Pedestrian Underpass Regarding to Chemical Hazards, Mashhad, Iran, Procedia - Social and Behavioral Sciences, No. 51;2012: 10-14.

[3] Mahdavinejad, M. Doroodgar, A. Moradchelleh, A. The Impacts of Revivalist Trends on the Contemporary Architecture of Iran (1977-2011), Middle-East Journal of Scientific Research, 2012; 11 (2):176-183.

[4] Mahdavinejad, M. The World Architectural Theories, 3th ed., Tehran: Jahad Publication Ltd - University of Tehran; 2012.

[5] Mahdavinejad, M. Moradchelleh, A. Family-Led Method in Art Education and Learning, Case: Tehran, Iran, Middle - East Journal of Scientific Research, 2011; 9 (4): 554-560.

[6] Mahdavinejad, M. Moradchelleh, A. Problems and Tendencies of the Development of the Architectural Sciences: Culture Research Aspect, Middle-East Journal of Scientific Research, 2011; 10 (6): 677-682.

[7] Mahdavinejad, M. Moradchelleh, A. The Impact of Family and Social Class on Efficiency of Arts Education and Learning, Middle-East Journal of Scientific Research 11 (8), 2012; 10681077. 
[8] Mahdavinejad, M. Moradchelleh, A. Problems and Tendencies of the Development of tSShe Architectural Sciences: Culture Research Aspect, Middle-East Journal of Scientific Research, 2011; 10 (6): 677-682.

[9] Mahdavinejad, M. Mansoori, S. Architectural Design Criteria of Socio-Behavioral Approach toward Healthy Model, Procedia Social and Behavioral Sciences,2012; Vol. 35, No. 1: 475-482.

[10] Tchobanoglous, G., Theisen, H. Integrated solid waste management, Mc Graw-Hill Inc; 1993.
[11] Abduli, mohammad ali, "Comprehensive plan for the recovery and disposal of MSW", first publish, Municipal Organization, Tehran; 2000.

[12] Shapourian, Seyedmohammadhadi, Using Recycled Material for Insulation, Thesis for MA degree in Energy \& Architecture, College of Fine Arts Faculty of Architecture, Tehran University, Iran; 2011. 